\title{
A COMPREHENSIVE STUDY ON DIFFERENT METHODS FOR AIR EXCHANGE RATES MEASUREMENT IN A NATURALLY VENTILATED DAIRY HOUSE
}

\author{
M. Samer*
}

\section{ABSTRACT}

The major problem of natural ventilation is the lack of accurate, continuous and online measuring and controlling techniques for air exchange rates (AER) which is crucial for the quantification of gaseous emissions. Therefore, this papers aims at comparing four measurement methods and to recommend thereof one method for further developments. Thirty six experiments were performed to study the AERs in a naturally ventilated dairy barn through four summer seasons and three winter seasons. The AERs were determined using moisture $\left(\mathrm{H}_{2} \mathrm{O}\right)$ balance, heat balance (HB), CO $\mathrm{C}_{2}$-balance and tracer gas technique (TGT). The statistical analyses were correlation analysis, regression model, ANOVA model and t-test. Continuous measurements of $\mathrm{CO}_{2}$ concentrations, temperature and relative humidity inside and outside the building were performed. The $\mathrm{H}_{2} \mathrm{O}$-balance showed reliable results through winter seasons and slightly acceptable results through summer seasons. The error sources of $\mathrm{H}_{2} \mathrm{O}$-balance are: the difference between the internal and external humidity levels which depend in turn on the accuracy of the used temperature-humidity sensors and their locations, the correctness of the used factors (e.g. the moisture produced by one cow and per mass unit), and the accuracy of the calculations of the humidity ratios. The HB showed acceptable results to some extent through summer seasons and unsatisfactory results through winter seasons. The error sources of $H B$ are: the calculations accuracy of the net area of the different building components and the determination of the relevant overall heat transfer coefficients, the temperature difference which depends in turn on the accuracy of the used temperature-humidity sensors and their locations,

\footnotetext{
*Assistant Professor, Cairo University, Faculty of Agriculture, Department of Agricultural Engineering, El-Gammaa Street, 12613 Giza, Egypt; e-mail: samer@cu.edu.eg
} 
and the sensible heat produced by the animals which depends on the physiological changes of the animals. The $\mathrm{CO}_{2}$-balance showed unexpected high differences to the other methods in some cases. The error sources of $\mathrm{CO}_{2}$-balance are: the use of calculation models for metabolic energy, the amount of $\mathrm{CO}_{2}$ produced per energy unit, the quantity of $\mathrm{CO}_{2}$ produced emitted from manure, variations of ambient temperatures and the location of $\mathrm{CO}_{2}$ measuring points. The TGT showed reliable results compared to $\mathrm{HB}, \mathrm{H}_{2} \mathrm{O}$-balance and $\mathrm{CO}_{2}$-balance. Therefore, the TGT should be further developed, where it delivers comparable results and is independent on the physiological parameters. The airflow rates (AFRs), subject to TGT, were $0.12 \mathrm{~m}^{3} \mathrm{~s}^{-1} \mathrm{~m}^{-2}, 1.15 \mathrm{~m}^{3} \mathrm{~s}$ ${ }^{1} \mathrm{cow}^{-1}, 0.88 \mathrm{~m}^{3} \mathrm{~s}^{-1} \mathrm{LU}^{-1}$ (LU is livestock unit of $500 \mathrm{~kg}$ ), $395 \mathrm{~m}^{3} \mathrm{~s}^{-1}$ and $470 \mathrm{~kg}$ air $\mathrm{s}^{-1}$ through summer seasons, and $0.08 \mathrm{~m}^{3} \mathrm{~s}^{-1} \mathrm{~m}^{-2}, 0.83 \mathrm{~m}^{3} \mathrm{~s}^{-1}$ cow $^{-1}, 0.64 \mathrm{~m}^{3} \mathrm{~s}^{-1} \mathrm{LU}^{-1}, 275 \mathrm{~m}^{3} \mathrm{~s}^{-1}$ and $328 \mathrm{~kg}$ air $\mathrm{s}^{-1}$ through winter seasons. The AERs were 37, 81, 63 and $62 \mathrm{~h}^{-1}$ through summer seasons, and 40, 143, 61 and $39 h^{-1}$ through winter seasons subject to $\mathrm{H}_{2} \mathrm{O}$ balance, $\mathrm{HB}, \mathrm{CO}_{2}$-balance and TGT, respectively.

Keywords. Livestock buildings, Heat balance, Moisture $\left(\mathrm{H}_{2} \mathrm{O}\right)$ balance, Tracer gas technique, $\mathrm{CO}_{2}$-balance, Natural ventilation, Airflow rates, Air exchange rates, Gaseous emissions.

\section{INTRODUCTION}

$\mathrm{N}$ atural ventilation is the movement of air through openings of a building by the use of the natural forces produced by wind and temperature difference. Simplicity, low initial costs and low energy costs are primary factors that make the natural ventilation most common type of ventilation. However, natural ventilation that is dependent on natural forces is inherently variable and consequently has numerous limitations (Hellickson and Walker, 1983). Ventilation measurements provide the means for understanding the mechanics of ventilation and air flow in the buildings (Liddament, 1996). According to Albright (1990), three important concepts underlie environmental analysis of buildings: (a) control volumes, (b) conservation of energy and (c) conservation of mass. The concept of energy conservation is applied to sensible heat, and mass conservation is applied to latent heat (humidity) and gaseous contaminants. In other words, the conservation of 
energy is applied to heat balance, and the mass conservation is applied to $\mathrm{H}_{2} \mathrm{O}$-balance and $\mathrm{CO}_{2}$-balance and the other gaseous contaminants. Hatem (1993) described some methods for ventilation rate measurements, thereof: heat balance, and $\mathrm{CO}_{2}$ and $\mathrm{H}_{2} \mathrm{O}$ mass balances. These methods largely depend on the animal production of heat, $\mathrm{CO}_{2}$ and $\mathrm{H}_{2} \mathrm{O}$. Sallvik (1999) elucidated the heat balance at animal level and the animal heat production. Teye and Hautala (2007) investigated the heat balance, $\mathrm{CO}_{2}$-balance and $\mathrm{H}_{2} \mathrm{O}$-balance. They concluded that the aforementioned methods are adequate for estimating the ventilation rates in naturally ventilated buildings.

Samer et al. (2011a) compared the radioactive tracer gas technique to two other methods for ventilation rate measurements, which are: $\mathrm{CO}_{2}$ balance, and the combined effects of wind pressure and temperature difference forces (WT-method). They found a good linear correlation between tracer gas technique and the $\mathrm{CO}_{2}$-balance, but they found no linear correlation between tracer gas technique and the WT-method which depends on wind velocity (speed and direction) that varies from moment to moment. On the other hand, the $\mathrm{CO}_{2}$-balance depends on animal production of $\mathrm{CO}_{2}$ which in turn depends on the metabolic energy. Therefore, they recommended further developing the radioactive tracer gas technique which delivers comparable results and is independent on physiological changes. Samer et al. (2011b,c) developed further the radioactive tracer gas technique and they concluded that the sum of radioactive impulses calculation method lead to better results. They added that considering all readings of the radiation counters is more representative for air movement. Samer et al. (2011b) stated that the release of radioactive tracer gas orthogonal to the prevailing wind at the windward side (over the manure alley) produced better detection by all radiation counters through summer seasons emphasizing better mixing of tracer gas with air and the better distribution of tracer inside the livestock building. Samer et al. (2011c) stated that the release of radioactive tracer gas from a fixed source point determined with smoke experiments is the best suited release method through winter seasons where the barn is totally closed. 
The determination of ventilation rates through naturally ventilated buildings is a key factor in quantifying emission flow rates from livestock buildings. There is a need to improve the accuracy of ventilation rate measurements because no accurate, reliable, and online method is available for ventilation rate measurement in naturally ventilated barns. Therefore, the objective of this study was to evaluate and compare the ventilation rates estimated using the following measurement methods: radioactive tracer gas technique, heat balance, $\mathrm{H}_{2} \mathrm{O}$-balance and $\mathrm{CO}_{2}$-balance. This paper summarizes the investigations carried out by Samer et al. (2011d, 2012).

\section{MATERIALS AND METHODS}

\section{Specifications of the Barn}

The measurements were carried out during 4 summer seasons and 3 winter seasons, in a naturally ventilated dairy barn located in north-east Germany (at latitude of 54 $4^{\prime} 1^{\prime \prime} \mathrm{N}$, longitude of $12^{\circ} 13^{\prime} 60^{\prime \prime} \mathrm{E}$, and altitude of $43 \mathrm{~m}$ ). The investigated dairy barn is surrounded by several agricultural buildings, except the southern and western sides. Fortunately, the prevailing summer winds are south to south-west winds. The dairy barn was $96.15 \mathrm{~m}$ long and $34.2 \mathrm{~m}$ wide. The roof top varied from $4.2 \mathrm{~m}$ at the side to $10.73 \mathrm{~m}$ at the gable top. The internal room volume of the barn amounted to $25,499 \mathrm{~m}^{3}\left(70 \mathrm{~m}^{3} \mathrm{cow}^{-1}\right)$, where the barn is designed to accommodate 364 dairy cows in loose housing system with freestalls. The manure handling system was equipped with winch-drawn dung channel scrapper. The dairy barn was naturally ventilated by air draft introduced into the building through adjustable curtains in the sidewalls (which were protected by nets and open in summer but closed in winter), open ridge slot, space boards of the gable walls, and open doors in the gable walls. During the summer seasons, three additional ceiling fans were used to enhance the uniformity of air distribution inside the barn. The fans were mounted to the ceiling along the building centerline and had a diameter of $7.2 \mathrm{~m}$ with a maximum discharge of $546,000 \mathrm{~m}^{3} \mathrm{~h}^{-1}$.

\section{Experimental Procedures}

The measurements were conducted over 2-week period per season, where the air temperature and relative humidity were measured inside and outside the building using 6 temperature-humidity sensors/loggers 
(THS). Furthermore, the concentration of $\mathrm{CO}_{2}$ was continuously measured, using a multi-gas monitor (INNOVA 1312, Innova AirTech Instruments, Ballerup, Denmark), inside the barn at 8 uniformly distributed sampling points (SP) and outside the barn at 4 points (Fig 1). A radioactive tracer gas was used for ventilation rate measurements, where the radioactive impulses were measured using 20 radiation counters (RC). The results were compared by performing Pearson correlation analyses and developing linear regression models as well as ttest. The differences to the reference method were tested using ANOVA model. The statistical analyses were conducted with SAS v.9.2 (SAS Institute, Cary, USA).

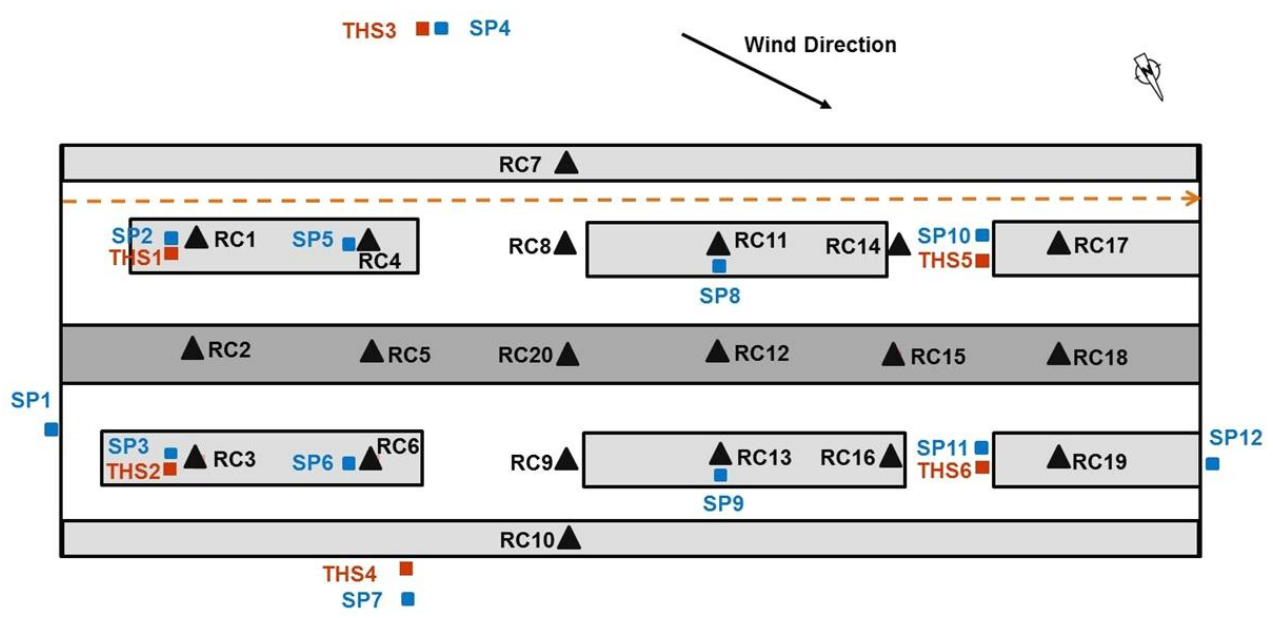

Figure 1. Plan view of the investigated barn, where $\mathrm{RC}$ is radiation counter, SP is gas sampling point, and THS is temperature-humidity sensor (Samer et al. 2012).

\section{Tracer Gas Technique}

The trace gas under consideration was Krypton-85, where the decay method of radioactive isotope ${ }^{85} \mathrm{Kr}$ was implemented. The tracer experiments were conducted between 4 and 6 times per campaign, i.e. investigation period. The tracer gas was released inside the building to determine the air exchange rate using the decay method, where ideal mixing of both air and tracer gas inside the building was assumed. The 
air exchange rate is then the result of an exponential relation between the impulses and the time. The tracer gas was released from a line source on the windward side of the building, orthogonal to the prevailing wind, over the manure alley (orange dash line, see Figure 1). Thirty six tracer gas experiments were conducted from 2006 to 2011, where 16 were in summer and 20 in winter. The duration of each tracer gas measurement was approx. $10 \mathrm{~min}$ including the release, decay, and idle time. The radioactive tracer gas was constantly released during each investigation and the decrease of impulses was measured for each release. Uncertainties with this method can be caused by inadequate mixing of the tracer gas in the air plenum of the building. The ventilation rate was calculated using the decay method of radioactive ${ }^{85} \mathrm{Kr}$ as follows:

$$
\begin{aligned}
& I=I_{0} \cdot e^{-\alpha \cdot t} \\
& \dot{V}_{T G T}=\alpha \cdot v
\end{aligned}
$$

Equation (2) is an exponential function, where I represents the impulses recorded by the radiation counters per second, $\mathrm{t}$ is the time in seconds, $\alpha$ (s-1) represents the air exchange rate per second, and I0 is the impulses at $\mathrm{t}=0$ (Gläser et al., 1986). The term $\alpha$ (s-1) should be converted to air exchange rate per hour in order to be used in Eq. (7) where, $v(\mathrm{~m} 3)$ is the volume of the building, and $\dot{V}_{T G T}(\mathrm{~m} 3 \mathrm{~h}-1)$ represents the ventilation rate estimated using the tracer gas technique.

\section{H2O-Balance}

Moisture, formed by animal respiration and by evaporation from manure and forages, can be used as a natural tracer gas. The ventilation rate throughout the building can be determined by calculating the mass balance of $\mathrm{H} 2 \mathrm{O}$ flow. The calculations of moisture balance were based on several studies (Albright, 1990; Hellickson and Walker, 1983; Teye and Hautala, 2007). The following mathematical model describes the moisture balance:

$$
Q_{H_{2} O}=\frac{v \cdot M_{W}}{W_{i}-W_{o}}
$$


Where, $Q_{\mathrm{H}_{2} \mathrm{O}}\left(\mathrm{m}^{3} \mathrm{~s}^{-1}\right)$ represents the ventilation rate subject to the $\mathrm{H}_{2} \mathrm{O}$-balance, $v\left(\mathrm{~m}^{3} \mathrm{~kg}^{-1}\right.$ dry air) is the air specific volume, $W_{i}\left(\mathrm{~g} \mathrm{H}_{2} \mathrm{O} \mathrm{Kg}^{-1}\right.$ dry air $)$ is the humidity ratio inside the building and $W_{o}\left(\mathrm{~g} \mathrm{H}_{2} \mathrm{O} \mathrm{Kg}^{-1}\right.$ dry air) is the humidity ratio outside the building. The humidity ratios were determined by the psychometrics software EZAir Properties v.1.3.5 (R. M. Parks, Gradyville, PA, USA) using the relative humidity and temperature measured by the temperaturehumidity sensors. $M_{W}\left(\mathrm{~g} \mathrm{H}_{2} \mathrm{O} \mathrm{s}^{-1}\right)$ represents the moisture produced by the cows housed in the building, and was calculated as follows:

$$
\begin{aligned}
& M_{W}=n \cdot m_{W} \\
& m_{W}=P_{\mathrm{H}_{2} \mathrm{O}} \cdot M_{\text {avg. }}
\end{aligned}
$$

Where, $\mathrm{n}$ represents the number of cows housed in the building, $\mathrm{mW}$ (g H2O s$1)$ is the moisture produced by one dairy cow, Mavg. $(\mathrm{kg})$ is the average mass of the cows, and $P_{\mathrm{H}_{2} \mathrm{O}}$ (g H2O h-1 kg-1) is the moisture produced by a dairy cow per mass unit which is 1.8 (Lindley and Whitaker, 1996).

\section{Heat Balance}

The heat balance was calculated as follows (Hellickson and Walker, 1983; Albright, 1990; Lindley and Whitaker, 1996):

$$
\dot{V}_{H B}=\frac{q_{s}-(\Sigma U A+F P) \cdot\left(t_{i}-t_{o}\right)}{C_{p} \cdot \rho \cdot\left(t_{i}-t_{o}\right)}
$$

Where, $\dot{V}_{H B}$ (m3 s-1) represents the ventilation rate, subject to the heat balance, and is later converted from $\mathrm{m} 3 \mathrm{~s}-1$ to $\mathrm{m} 3 \mathrm{~h}-1$ to be comparable with the other methods; $q_{s}(\mathrm{~W})$ is the sensible heat produced by the animals and is estimated using the energy calculation model (Samer et al., 2011b); $U$ (W m-2 oC-1) represents the overall heat transfer coefficient of the building component under consideration and $A(\mathrm{~m} 2)$ is its area; the factor $\Sigma U A_{\text {characterizes the overall }}$ conductance of the building shell and includes the effects of ceiling, walls, windows, and doors; $F(\mathrm{~W}$ m-1 oC-1) represents the perimeter heat loss factor and was considered as $1.5 \mathrm{~W} \mathrm{~m}-1$ oC-1 (Albright, 1990); $P(\mathrm{~m})$ is the perimeter 
length of the building under consideration; $C_{p}(\mathrm{~J} \mathrm{~kg}-1$ oC-1) represents the specific heat of the air which was considered as $1006 \mathrm{~J} \mathrm{~kg}-1$ oC-1 according to Albright (1990), $\rho^{\rho}(\mathrm{kg} \mathrm{m}-3)$ is the air density and is the inverse of the specific volume which was derived from the psychrometric charts using the dray-bulb temperature and the relative humidity; ${ }^{t}(\mathrm{oC})$ is the air temperature inside the barn, and $t_{o}(\mathrm{oC})$ is the air temperature outside the barn.

\section{$\mathrm{CO}_{2}$-Balance}

The carbon dioxide balance was calculated as follows (Hellickson and Walker, 1983; CIGR, 1984; Albright, 1990; CIGR, 2002):

$$
\dot{V}_{\mathrm{CO}_{2}}=\frac{n \cdot P_{\mathrm{CO}_{2}}}{C_{i}-C_{o}}
$$

Where, $P_{\mathrm{CO}_{2}}\left(\mathrm{mg} \mathrm{h}^{-1} \mathrm{cow}^{-1}\right)$ represents the excretion rate of $\mathrm{CO}_{2}$ from one cow, $n$ is the number of cows housed inside the building, $\dot{V}_{\mathrm{CO}_{2}}\left(\mathrm{~m}^{3} \mathrm{~h}^{-1}\right)$ is the ventilation rate calculated subject to $\mathrm{CO}_{2}$-balance which was set as reference method, and $C_{i}\left(\mathrm{mg} \mathrm{m}^{-3}\right)$ and $C_{o}\left(\mathrm{mg} \mathrm{m} \mathrm{m}^{-3}\right)$ are the concentrations of the gas inside and outside the building, respectively. The air exchange rate can be then calculated by dividing the ventilation rate by the volume of the building.

\section{RESULTS AND DISCUSSION}

Generally, the $\mathrm{H}_{2} \mathrm{O}$-balance showed slightly acceptable results through summer seasons (Figs. 2a and 3a) on the one hand and reliable results through winter seasons (Figs. $2 b$ and $3 b$ ) on the other hand. In summer, the $\mathrm{H}_{2} \mathrm{O}$-balance delivers comparable results to TGT and $\mathrm{CO}_{2}$-balance. However, the overall deviations between the methods are too high, which does not allow specifying the most suitable method for summer. In winter, the $\mathrm{H}_{2} \mathrm{O}$-balance shows better results. Overall, all three methods showed good agreements in winter except for some inaccuracies in $\mathrm{CO}_{2-}$ balance. Provided some improvements to the $\mathrm{CO}_{2}$-balance the three methods deliver similar and satisfactory results through winter seasons. The $\mathrm{H}_{2} \mathrm{O}$-balance has some error sources, which are: the difference between the internal and external humidity levels which depend in turn 
on the accuracy of the used temperature-humidity sensors and the suitability of their locations, the correctness of the used factors (e.g. the moisture produced by one cow and per mass unit), and the accuracy of the calculations related to the humidity ratios.

The HB delivers comparable results to the TGT and $\mathrm{CO}_{2}$-balance (Figs. $4 \mathrm{a}$ and 5a) through summer seasons and inaccurate results through winter seasons (Figs. 4b and 5b). However, the overall deviations between the methods are too high, which does not allow specifying the most suitable method due to the variable climatic conditions that affect all methods. Hence, all methods should be enhanced. Concerning the HB, the error sources are: the accuracy of the calculations related to the net area of the different building components and the determination of the relevant overall heat transfer coefficients, the temperature difference which depends in turn on the accuracy of the used temperature-humidity sensors and the suitability of their locations, and the sensible heat produced by the animals which depends on the physiological changes.

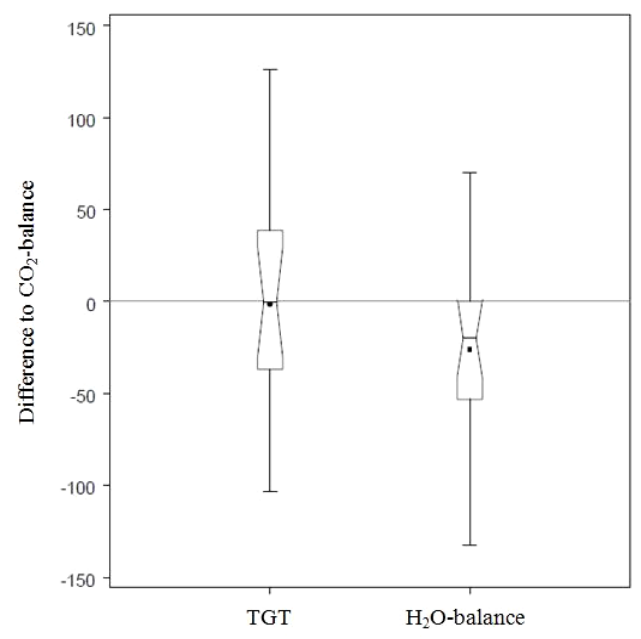

(a)

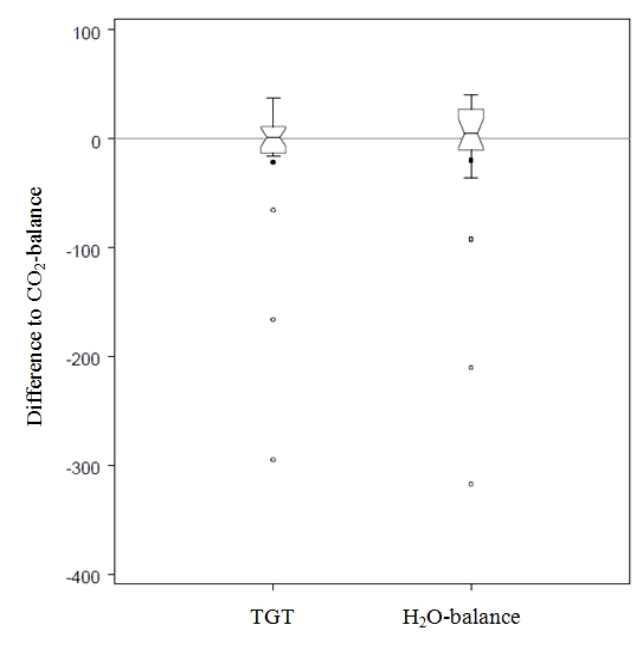

(b)

Figure 2. Distributions of the differences in $\mathrm{h}^{-1}$ between TGT and $\mathrm{CO}_{2}$ balance on the one hand and $\mathrm{H}_{2} \mathrm{O}$-balance and $\mathrm{CO}_{2}$-balance on the other hand, where (a) is for summer and (b) for winter. The solid dots represent the averages, the internal dashes designate the medians, and the upper and lower external dashes are the maximal and minimal values within 1.5 times the interquartile range (Samer et al. 2012). 


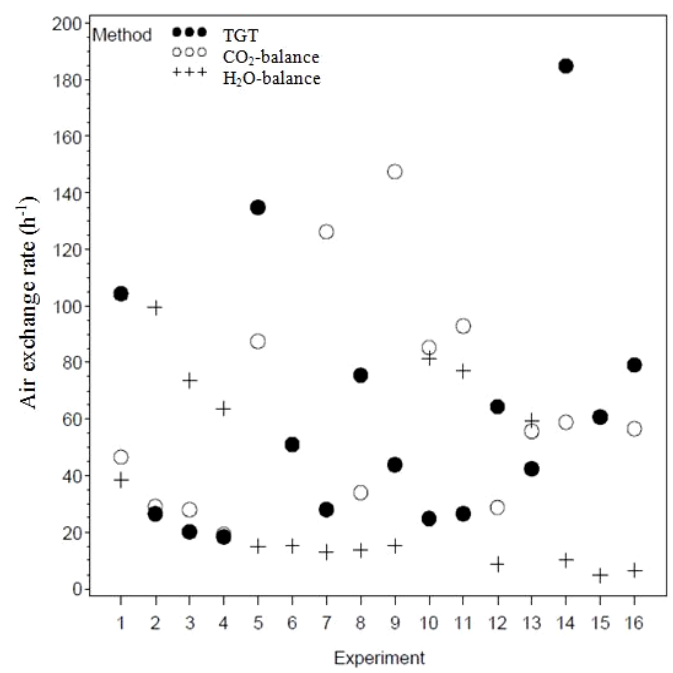

(a)

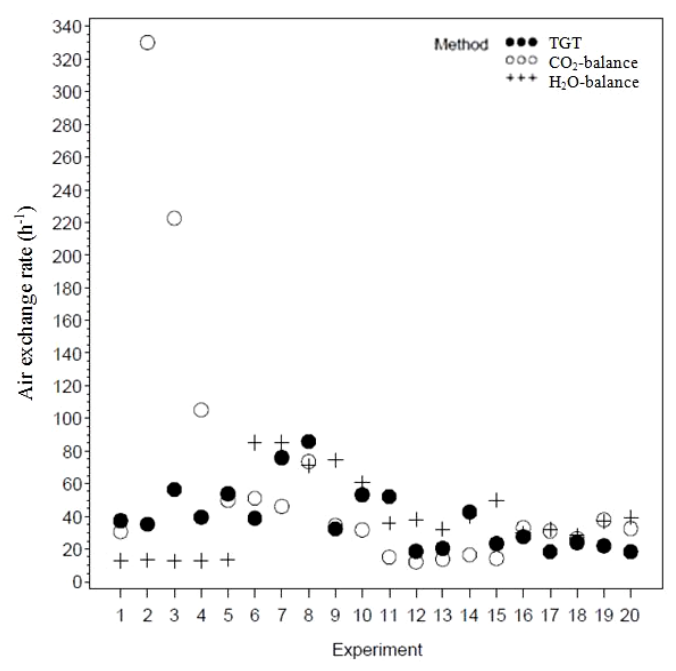

(b)

Figure 3. AERs subject to TGT, $\mathrm{H}_{2} \mathrm{O}$-balance and $\mathrm{CO}_{2}$-balance during the different experiments, where (a) is for summer and (b) for winter (Samer et al. 2012).

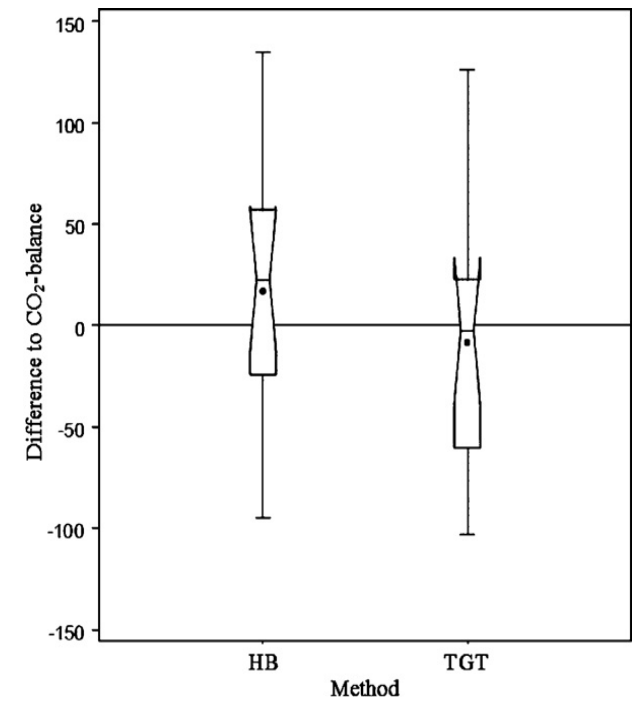

(a)

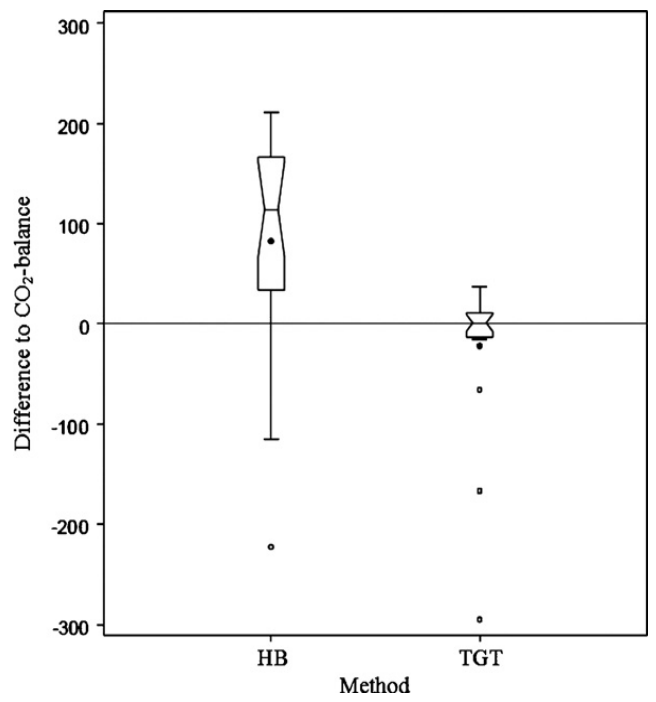

(b)

Figure 4. Distributions of the differences in $\mathrm{h}^{-1}$ between TGT and $\mathrm{CO}_{2}$-balance on the one hand and $\mathrm{HB}$ and $\mathrm{CO}_{2}$-balance on the other hand, where (a) is for summer and (b) for winter. The solid dots represent the averages, the internal dashes designate the medians, and the upper and lower external dashes are the maximal and minimal values within 1.5 times the interquartile range (Samer et al. 2011d). 


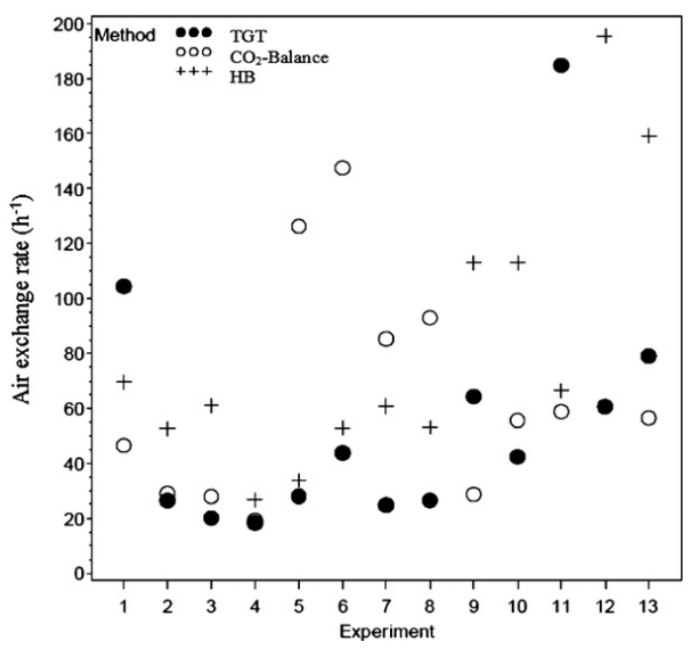

(a)

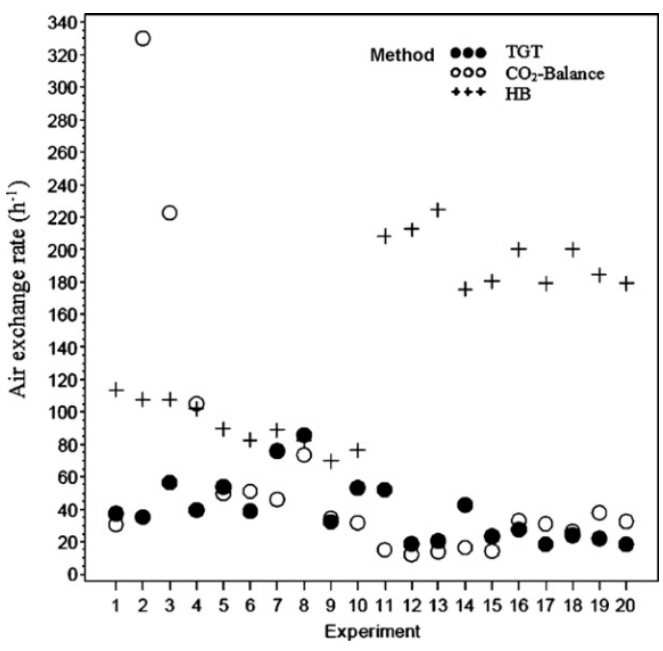

(b)

Figure 5. AERs subject to TGT, $\mathrm{HB}$ and $\mathrm{CO}_{2}$-balance during the different experiments, where (a) is for summer and (b) for winter (Samer et al. 2011d).

The $\mathrm{CO}_{2}$-balance is not in general use a reference to measure air exchange rates owing to several error sources that can have negative impacts, such as the calculation of metabolic energy, the $\mathrm{CO}_{2}$ produced per energy unit, the amount of $\mathrm{CO}_{2}$ produced by manure, and the location of the $\mathrm{CO}_{2}$ sampling points. However, in this study, the $\mathrm{CO}_{2}$-balance was set as a reference because comparison with other accurate methods is not possible. Hence, the $\mathrm{CO}_{2}$-balance should be enhanced using the lowest $\mathrm{CO}_{2}$ concentrations among the external measuring points to avoid overestimation through very low differences between internal and external $\mathrm{CO}_{2}$ concentrations.

The TGT showed reliable results in comparison to $\mathrm{H}_{2} \mathrm{O}$-balance through winter seasons, and more accurate results through summer seasons. On the other hand, the TGT showed reliable results in comparison to the HB which showed slightly acceptable results through summer seasons on the one hand and unsatisfactory results through winter seasons on the other hand. Additionally, the TGT is more reliable than $\mathrm{CO}_{2}$-balance that showed unexpected high differences to the other methods in some cases (Figs. $3 b$ and $5 b$ ). Therefore, the TGT should be further developed, 
where it delivers comparable results and is independent on the physiological parameters. Although the TGT was previously improved (Samer et al., 2011b, 2011c); further improvements are required and should focus on developing and enhancing the calculation method. The airflow rates subject to the different methods are summarized in Table1.

Based on the above, a perspective has been formulated which is implementing at least three measurement methods, to simultaneously measure the ventilation rate in a naturally ventilated building as follows: (1) TGT, $\mathrm{CO}_{2}$-balance and $\mathrm{HB}$ in summer, and (2) TGT, $\mathrm{CO}_{2}$-balance and $\mathrm{H}_{2} \mathrm{O}$-balance in winter. Besides, a fifth method can be implemented, which is the combined effect of wind pressure and thermal buoyancy, i.e. the WT-method, which was implemented by Samer et al. (2011a). When two of three measurement methods or three of four methods agree, the agreed value is then considered and the irregular value is ruled out.

Table 1. Airflow rates subject to the different methods (Samer et al., 2011d, 2012).

\begin{tabular}{|c|c|c|c|c|c|c|c|}
\hline $\begin{array}{l}\tilde{D} \\
\text { 吕 } \\
\text { D. } \\
\text { D. }\end{array}$ & Method & $\begin{array}{c}\text { AER } \\
\mathrm{h}^{-1} \\
\end{array}$ & $\begin{array}{c}\dot{V} \\
\mathrm{~m}^{3} \mathrm{~s}^{-1}\end{array}$ & $\begin{array}{c}\text { Airflow rate } \\
\text { per unit area } \\
\mathrm{m}^{3} \mathrm{~s}^{-1} \mathrm{~m}^{-2} \\
\end{array}$ & $\begin{array}{l}\text { Airflow rate per cow } \\
\qquad \mathrm{m}^{3} \mathrm{~s}^{-1} \text { cow }^{-1}\end{array}$ & $\begin{array}{c}\text { Airflow rate } \\
\text { per LU } \\
\mathrm{m}^{3} \mathrm{~s}^{-1} \mathrm{LU}^{-1} \\
\end{array}$ & $\begin{array}{c}\dot{M} \\
\mathrm{~kg} \mathrm{~s}^{-1}\end{array}$ \\
\hline \multirow{4}{*}{ 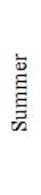 } & $\mathrm{HB}$ & 81.40 & 577 & 0.18 & 1.68 & 1.29 & 686 \\
\hline & $\mathrm{H}_{2} \mathrm{O}$-balance & 37.21 & 264 & 0.08 & 0.75 & 0.58 & 314 \\
\hline & TGT & 55.76 & 395 & 0.12 & 1.15 & 0.88 & 470 \\
\hline & $\mathrm{CO}_{2}$-balance & 64.34 & 456 & 0.14 & 1.32 & 1.02 & 542 \\
\hline \multirow{4}{*}{$\frac{\text { 总 }}{\underline{\Xi}}$} & $\mathrm{HB}$ & 143 & 1014 & 0.31 & 3 & 2.31 & 1207 \\
\hline & $\mathrm{H}_{2} \mathrm{O}$-balance & 40.26 & 285 & 0.09 & 0.86 & 0.66 & 339 \\
\hline & TGT & 38.88 & 275 & 0.08 & 0.83 & 0.64 & 328 \\
\hline & $\mathrm{CO}_{2}$-balance & 60.46 & 428 & 0.13 & 1.29 & 0.99 & 510 \\
\hline
\end{tabular}

The results differ from summer to winter; this can be attributed to the seasonal variations of temperature and humidity which affect the heat balance and the moisture balance, respectively. Additionally, the barn is totally closed in winter where the ventilation rate through a naturally ventilated barn is dependent on wind velocity (Samer et al., 2011e). Several studies were carried out to investigate the ventilation rate with radioactive tracer gas technique and recommended to developing further 
this technique which is independent on physiological changes and variations of temperature and humidity (Samer et al., 2011f,g,h). A key issue is to monitor the climatic variations (wind velocity, temperature and humidity) outside the naturally ventilated building throughout the experiments using a weather station, and the indoor air temperature and humidity using temperature-humidity sensors as well as the indoor air velocity using anemometers where a computer program was developed for monitoring and controlling ultrasonic anemometers for aerodynamic measurements in animal housing (Samer et al., 2011e,i).

\section{Safety Emphasis}

Regarding the cows, the natural radioactivity of meat is $100 \mathrm{~Bq} \mathrm{~kg}^{-1}$ (LLBB, 2005). Through the TGT experiments, one cow receives 0.688 $\mathrm{Bq} \mathrm{kg}^{-1}$. Regarding the workers, adults have natural "internal" radioactivity of 9000-10000 $\mathrm{Bq}$ (BfS, 1993) owing to the fact that the body contains radioactive isotopes ${ }^{40} \mathrm{~K}$ and ${ }^{14} \mathrm{C}$. Through the TGT experiments, one worker receives $470.6 \mathrm{~Bq}$. For more information regarding the safety of implementing radioactive tracer refer to Samer et al. (2011a,b).

\section{CONCLUSIONS}

Both $\mathrm{H}_{2} \mathrm{O}$-balance and $\mathrm{CO}_{2}$-balance, which are mass balances, are able to continuously determine the ventilation rates through naturally ventilated buildings. However, they are dependent on physiological changes in animals and they have several error sources: locations of the different measuring points, calculation models, accuracy of $\mathrm{H}_{2} \mathrm{O}$ and $\mathrm{CO}_{2}$ production rates per animal unit or cow, and the amount of $\mathrm{H}_{2} \mathrm{O}$ and $\mathrm{CO}_{2}$ released from manure. The heat balance, which is a continuous ventilation rate measurement method, showed inaccuracies especially through winter seasons. The error sources of heat balance are: the accuracy of the calculations related to the net area of the different building components and the determination of the relevant overall heat transfer coefficients, the temperature difference which depends in turn on the accuracy of the used temperature-humidity sensors and the suitability of their locations, and the sensible heat produced by the animals which depends on the physiological changes in animals as bio-response to 
changes in ambient micro-environmental conditions. The radioactive tracer gas technique showed reliable results in comparison to $\mathrm{H}_{2} \mathrm{O}$ blance, $\mathrm{CO}_{2}$-balance and heat balance. Additionally, this technique is independent on physiological parameters and variations of temperature and humidity, and is safe. However, it is a discontinuous ventilation rate measurement method and is dependent on wind velocity (direction and speed). The overall deviations between the methods are high, which does not allow specifying the most suitable method due to the variable climatic conditions that affect all methods. Hence, all methods should be enhanced. A perspective is to implement at least three measurement methods, to simultaneously measure the ventilation rate in a naturally ventilated building as follows: (1) TGT, $\mathrm{CO}_{2}$-balance and $\mathrm{HB}$ in summer, and (2) TGT, $\mathrm{CO}_{2}$-balance and $\mathrm{H}_{2} \mathrm{O}$-balance in winter. Besides, a fifth method can be implemented, which is the combined effect of wind pressure and thermal buoyancy (WT-method). When two of three measurement methods or three of four methods agree, the agreed value is then considered and the irregular value is ruled out.

\section{Acknowledgements}

The authors would like to acknowledge U. Stollberg, K. Schröter and D. Werner, technicians at the Department of Engineering for Livestock Management at the Leibniz Institute for Agricultural Engineering Potsdam-Bornim (ATB) in Germany, for their technical and logistical support during the measurements campaigns. Furthermore, we gratefully acknowledge the contribution of C. Loebsin and O. Tober, technicians at the Institute for Animal Production, State Institute for Agriculture and Fishery MV, Dummerstorf, Germany.

\section{REFERENCES}

Albright, L. D. 1990. Environment Control for Animals and Plants. St. Joseph, Michigan, USA: ASAE.

BfS. 1993. Radiation and radiation protection. Information brochure. Salzgitter, Germany: Federal Office for Radiation Protection. 
CIGR. 2002. Climatization of animal houses. In S. Pedersen, \& K. Sallvik (Eds.), Climatization of animal houses. Working Group Report on: Heat and moisture production at animal and house level. Denmark: DIAS, ISBN 87-88976-60-2.

CIGR. 1984. Climatization of animal houses. Working Group Report on: Climatization of animal houses. Scotland, UK: International Commission of Agricultural Engineering (CIGR).

Gläser, M., Klich, W., \& Creifelds, A. 1986. Vergleichende Untersuchungen an ${ }^{85} \mathrm{Kr}$ und ${ }^{133} \mathrm{Xe}$ als Tracer, in German (Comparison between ${ }^{85} \mathrm{Kr}$ and ${ }^{133} \mathrm{Xe}$ as tracer). Isotopenpraxis, 22(11), 411-416.

Hatem, M. H. 1993. Theory of Structures and Agricultural Buildings, and Environmental Control (2 ${ }^{\text {nd }}$ ed.). Egypt: Faculty of Agriculture, Cairo University.

Hellickson, M. A., and Walker, J. N. 1983. Ventilation of Agricultural Structures. St. Joseph, Michigan, USA: ASAE.

Liddament, M. 1996. A Guide to Energy Efficient Ventilation. IEA Energy Conservation in Buildings and Community Systems Programme, Annex V Air Infiltration and Ventilation Centre, Coventry, England.

Lindley, J. A., and Whitaker, J.H. 1996. Agricultural Buildings and Structures. St. Joseph, Michigan, USA: ASAE.

LLBB. 2005. Jahresbericht Verbraucherschutz und Gesundheitsschutz fur Mensch und Tier: Umweltschutz und nachhaltiger Ressourcenschutz, in German (Annual report on consumer and health protection for people and animals: Environmental protection and sustainable resource protection). Berlin, Germany: BerlinBrandenburg State Laboratory. 
Sallvik, K. 1999. Environment for Animals. In E. Bartali, A. Jongebreur, \& D. Moffitt (Eds.), CIGR Handbook of Agricultural Engineering, Vol. 2 (pp. 31-88). St. Joseph, Michigan, USA: ASAE.

Samer, M., C. Ammon, C. Loebsin, M. Fiedler, W. Berg, P. Sanftleben, R. Brunsch. 2012. Moisture balance and tracer gas technique for ventilation rates measurement and greenhouse gases and ammonia emissions quantification in naturally ventilated buildings. Building and Environment, Vol. 50(4): 10-20.

Samer, M., W. Berg, H.-J. Müller, M. Fiedler, M. Gläser, C. Ammon, P. Sanftleben, and R. Brunsch. 2011a. Radioactive ${ }^{85} \mathrm{Kr}$ and $\mathrm{CO}_{2^{-}}$ balance for ventilation rate measurements and gaseous emissions quantification through naturally ventilated barns. Transactions of the ASABE, Vol. 54(3): 1137-1148.

Samer, M., H.-J. Müller, M. Fiedler, C. Ammon, M. Gläser, W. Berg, P. Sanftleben, and R. Brunsch. 2011b. Developing the ${ }^{85} \mathrm{Kr}$ tracer gas technique for air exchange rate measurements in naturally ventilated animal buildings. Biosystems Engineering, Vol. 109(4): 276-287.

Samer, M., M. Fiedler, H.-J. Müller, M. Gläser, C. Ammon, W. Berg, P. Sanftleben, R. Brunsch. 2011c. Winter measurements of air exchange rates using tracer gas technique and quantification of gaseous emissions from a naturally ventilated dairy barn. Applied Engineering in Agriculture, Vol. 27(6): 1015-1025.

Samer, M., C. Loebsin, M. Fiedler, C. Ammon, W. Berg, P. Sanftleben, R. Brunsch. 2011d. Heat balance and tracer gas technique for airflow rates measurement and gaseous emissions quantification in naturally ventilated livestock buildings. Energy and Buildings, Vol. 43(12): 3718-3728.

Samer, M., C. Loebsin, K. von Bobrutzki, M. Fiedler, C. Ammon, W. Berg, P. Sanftleben, and R. Brunsch. 2011e. A computer program 
for monitoring and controlling ultrasonic anemometers for aerodynamic measurements in animal buildings. Computers and Electronics in Agriculture, Vol. 79(1): 1-12.

Samer, M., M. Fiedler, C. Loebsin, W. Berg, H.-J. Müller, M. Gläser, C. Ammon, P. Sanftleben, and R. Brunsch. 2011f. Tracer gas technique to estimate the ventilation rate through a naturally ventilated dairy barn. Landtechnik, Vol. 66(4): 286-288.

Samer, M., W. Berg, M. Fiedler, H.-J. Müller, M. Gläser, C. Ammon, R. Brunsch, C. Loebsin, O. Tober, P. Sanftleben. 2011g. Implementation of Radioactive ${ }^{85} \mathrm{Kr}$ for Ventilation Rate Measurements in Dairy Barns. Proceedings of the 2011 American Society of Agricultural and Biological Engineers (ASABE) Annual International Meeting, pp. 847-863, Paper No. 1110679, Louisville, Kentucky, USA.

Samer, M., M. Fiedler, K. von Bobrutzki, W. Berg, H.-J. Müller, M. Gläser, C. Ammon, C. Loebsin, O. Tober, P. Sanftleben, R. Brunsch. 2011h. Luftwechselmessungen im freigelüfteten Milchviehstall, in German (Measurements of air exchange rates in a naturally ventilated dairy barn). Tagung des Förderkreises Stallklima (Annual Conference on Supporting Stable Climate), 56.10.2011, Dummerstorf, Germany.

Samer, M., K. von Bobrutzki, W. Berg, A. Kiwan and D. Werner. 2011 i. A computer program for monitoring and controlling ultrasonic anemometers for aerodynamic measurements in animal housing. Proceedings of the $5^{\text {th }}$ European Conference on Precision Livestock Farming, pp. 506-516, Czech Centre for Science and Society, Prague, Czech Republic.

Teye, F. K., and Hautala, M. 2007. Measuring ventilation rates in dairy buildings. International Journal of Ventilation, 6(3), 247-256. 


\section{الملخص العربي \\ دراسة شاملة لطرق مختلفة لقياس معدلات التهوية الطبيعية بمساكن الابقار الحلابة \\ *.}

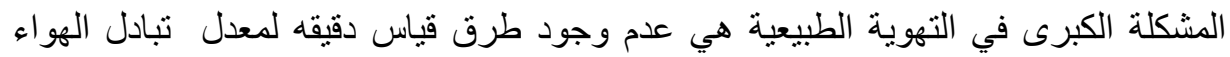

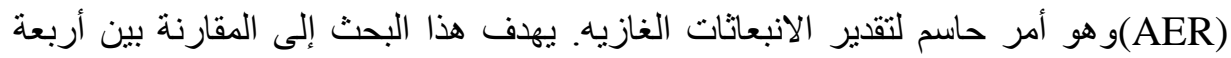

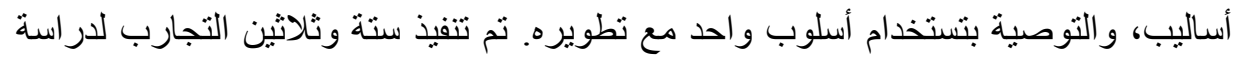

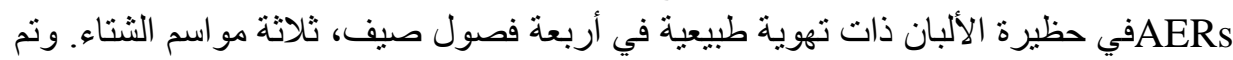
تحديد AERs باستخدام ميزان الرطوبة (HB

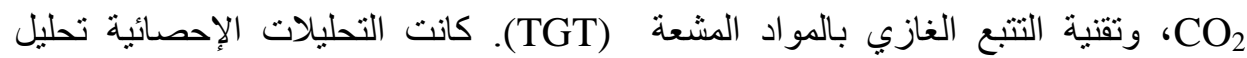

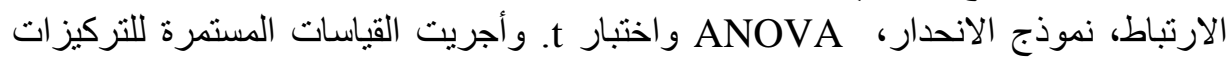
$\mathrm{H}_{2} \mathrm{O} \mathrm{CO}_{2}$

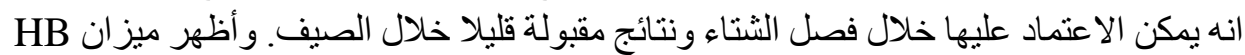

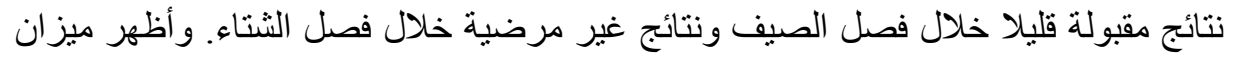

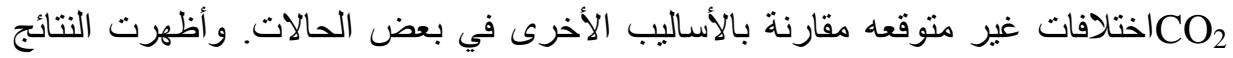

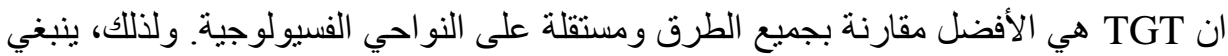

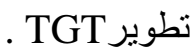

*مدرس - قسم الهندة الزراعيةـ كلية الزراعة - جامعة القاهرة. 